\title{
Profile of HIV subtypes in HIV/HBV- and HIV/HCV- coinfected patients in Southern Brazil
}

\author{
Valéria Miranda Avanzi ${ }^{[1]}$, Bianca Arão Vicente ${ }^{[2]}$, Nayara Carvalho Polido Beloto ${ }^{[1]}$, \\ Monica Maria Gomes-da-Silva ${ }^{[2]}$, Clea Elisa Lopes Ribeiro ${ }^{[2],[3], ~ F e l i p e ~ F r a n c i s c o ~ T u o n ~}{ }^{[1],[2],}$ \\ Luine Rosele Renaud Vidal[4], Meri Bordignon Nogueira ${ }^{[4]}$ and Sonia Mara Raboni ${ }^{[1],[2],}$
}

\begin{abstract}
[1]. Programa de Pós Graduação em Medicina Interna, Universidade Federal do Paraná, Curitiba, PR, Brasil. [2]. Departamento de Doenças Infecciosas, Universidade Federal do Paraná, Curitiba, PR, Brasil. [3]. Secretaria Municipal de Saúde de Curitiba, Divisão Epidemiologica, Curitiba, PR, Brasil.

[4]. Laboratório de Virologia, Universidade Federal do Paraná, Curitiba, PR, Brasil.
\end{abstract}

\begin{abstract}
Introduction: HIV and viral hepatitis infections are major causes of chronic disease worldwide and have some similarities with regard to routes of transmission, epidemiology, front barriers faced during access of treatment, and strategies for a global public health response. The objective was to describe the HIV-1 subtypes, viral tropism and single-nucleotide polymorphisms (SNPs) of interleukin 28B (IL28B) from a case series of HIV/viral hepatitis coinfected patients from southern Brazil. Methods: Clinical and epidemiological data were evaluated by a review of medical records. Periodic blood draws were taken to determine the viral and host characteristics. Results: This study included 38 patients with HIV/HBV or HIV/HCV coinfection; the median age was 49 years. Thirty-seven (97.4\%) were on antiretroviral therapy, $32(84.2 \%)$ had an undetectable viral load, a median CD4 ${ }^{+} \mathrm{T}-$ cell count of 452 cells $/ \mathrm{mm}^{3}$. HIV-1 subtyping showed 47.4 and $31.6 \%$ of patients with subtypes C and B, respectively. Analysis of viral co-receptor usage showed a predominance of the R5 variant (64.7\%), with no significant difference between the subtypes. Twenty patients with HIV/HCV coinfection were eligible to receive HCV therapy with pegylated-interferon-alpha plus ribavirin, and 10/20 (50\%) of them achieved sustained virological response. SNPs of IL28B were evaluated in $93.3 \%$ of patients with HIV/ HCV coinfection, and $17(60.7 \%)$ presented the CC genotype. Conclusions: In the present case series, a higher frequency of HIV subtype $\mathrm{C}$ was found in coinfected patients. However such findings need to be prospectively evaluated with the inclusion of data from regional multicenter analyses.
\end{abstract}

Keywords: HIV. hepatitis C virus. hepatitis B virus. Coinfection. CCR5. IL28B.

\section{INTRODUCTION}

It has been estimated that $30 \%$ of people living with human immunodeficiency virus/acquired immunodeficiency syndrome (PLWHA) are coinfected with hepatitis $\mathrm{C}$ virus $(\mathrm{HCV})$ or hepatitis B virus (HBV) ${ }^{1}$ However, the prevalence of these coinfections is variable, reflecting differences in the regional sociodemographic profile and hepatitis B immunization coverage 2 . In Brazil, the prevalence of HIV/HCV coinfection ranged from $3.3 \%$ to $82.4 \%$, with an average of around $20.3 \%{ }^{3}$. The introduction of highly active antiretroviral therapy (HAART) for PLWHA has increased their life expectancy, and chronic liver disease has become common among coinfected individuals, being the most frequent cause of hospitalization and mortality in these patients ${ }^{4}$. Meanwhile, the effect of coinfection

Corresponding author: Dra. Sonia Mara Raboni.

e-mail: sraboni@ufpr.br

Received 25 October 2016

Accepted 30 June 2017 on HIV evolution is not completely understood; these patients present with frequent hepatotoxicity after HAART, and drug resistance, which can lead to treatment failure and limitations in alternative treatment regimens ${ }^{5}$.

In Brazil, HIV diversity is driven by the co-circulation of HIV-1 subtypes $\mathrm{B}, \mathrm{C}$, and $\mathrm{F} 1$. In recent years, several HIV-1 recombinant forms, mainly $\mathrm{BF} 1$ and $\mathrm{BC}$ subtypes, have frequently been reported ${ }^{6}$. This viral diversity, albeit controversial, may have some effect on transmission patterns, pathogenicity, therapy, and immune response. In addition, it is associated with various host cells and viral mechanisms. In the context of HIV/viral hepatitis coinfection, there are no reports on the genetic profile of HIV infection and the host immunological profile of these coinfected individuals in Brazil, as well as its effect on hepatic and HIV infection progression. This study aimed to describe the HIV subtypes and the epidemiological, immunological, and clinical profiles of HIV/viral hepatitiscoinfected patients from a reference center in the State of Paraná, Southern Brazil. 


\section{METHODS}

\section{Study participants}

A cross-sectional study was conducted, in which coinfected outpatients identified in the referral clinics of Hospital de Clínicas - Universidade Federal do Paraná (HC/UFPR) from March 2011 to December 2015 were prospectively included. This tertiary-care academic hospital is the largest HIV referral center in the State of Paraná, southern Brazil, where 1,400 PLWH are currently being followed up, with HIV/HBV and $\mathrm{HIV} / \mathrm{HCV}$ coinfection rates of approximately $1.3 \%$ and $4 \%$, respectively ${ }^{7}$. HIV/HBV- or HIV/HCV-coinfected patients were enrolled in the study according to the following inclusion criteria: age $>18$ years; positive serology for HIV (anti-HIV), positive serology for HBV (HBV-surface antigen or DNA), and/or polymerase chain reaction (PCR)-positive $\mathrm{HCV}$; and voluntary participation by providing written informed consent. Patients with incomplete medical records, children, and those who did not agree to participate in the study were excluded. All information related to clinical, demographic and epidemiological data were obtained through a structured questionnaire and review of medical records. Venous blood was collected from the enrolled patients. The Institutional Review Board of $\mathrm{HC} /$ UFPR approved the study (IRB\# 2304.198/2010/08).

\section{Proviral DNA extraction, PCR amplification, and HIV-1 sequencing}

A concentration of $10^{7}$ peripheral blood mononuclear cells was separated by density gradient centrifugation (Histopaque ${ }^{\circledR} 1077-$ Sigma-Aldrich, St. Louis, MO, USA). Proviral HIV-1 DNA was extracted using a commercial QIAmp DNA Blood Kit ${ }^{\mathbb{B}}$ (Qiagen, Hilden, Germany) according to the manufacturer's protocol.

Fragments of the pol (HXB2 clone positions 2077-3574) and env (HXB2 clone positions 7001-7667) genes were generated by nested PCR according to a previously reported method ${ }^{8,9}$. The DNA fragments were purified and sequenced with the BigDye ${ }^{\circledR}$ Terminator v3.1 Cycle Sequencing Kit and the automated DNA sequencer (ABI 3500xL Genetic Analyzer; Applied Biosystems, Waltham, MA, USA) according to the manufacturer's instructions.

\section{Analysis of the genetic diversity of HIV-1}

Nucleotide sequences were edited using DNASTAR Lasergene SeqMan software v7.0 (DNAstar Inc., Madison, WI, USA). For performing maximum likelihood phylogenetic analyses, HIV-1 group M subtype reference sequences of HIV-1 subtypes were retrieved from the Los Alamos database, (http://www.hiv.lanl.gov/components/sequence/ $\mathrm{HIV} / \mathrm{search} / \mathrm{search} . h \mathrm{tml}$ ), and the tree was constructed using the best model with the algorithm implemented in the MEGA 6.0 package $^{10}$. Recombination analysis was performed by bootscanning analysis using Simplot 3.5.1 software $^{11}$. The subtype assignment of sequences was confirmed using the REGA HIV Subtyping Tool v.3.0 (http://hivdb.stanford.edu/ RegaSubtyping/stanford-hiv/typingtool/http://hivdb.stanford. edu/RegaSubtyping/stanford-hiv/typingtool/http://hivdb. stanford.edu/RegaSubtyping/stanford-hiv/typingtool/http:// hivdb.stanford.edu/RegaSubtyping/stanford-hiv/typingtool/).

\section{Resistance analysis}

The resistance-associated mutation profile and antiretroviral (ARV) susceptibility were inferred by submitting the PR/ RT sequences to the Calibrated Population Resistance Tool (v5.0 beta; http://cpr.stanford.edu/cpr/servlet/CPR) and the INT sequences to the Stanford HIV Resistance Database (http:// hivdb.stanford.edu/).

\section{Characterization of the CCR5 polymorphism and} determination of HIV-1 co-receptor tropism phenotype

CCR5 receptor polymorphisms were analyzed in blood samples by PCR as previously described ${ }^{12}$. Genotypic tropism test was performed using HIV envelope V3 loop sequences. Viral co-receptor usage predictions based on $\mathrm{V} 3$ sequences were performed by 11/25 rules, using Geno2pheno (http://coreceptor. bioinf.mpisb.mpg.de/cgi-bin/coreceptor.pl) with a false-positive rate of 0.1 , and using the Phenoseq platform (https://www. burnet.edu.au/facilities/9_phenoseq).

\section{Testing for SNPs of IL28B}

The single-nucleotide polymorphism (SNP) rs12979860 in the region of the interleukin 28B (IL28B) gene was analyzed using confronting two-pair primers as previously described ${ }^{13}$.

\section{Statistical analyses}

Demographic, epidemiological, clinical, and genetic data were compiled and analyzed using GraphPad Prism ${ }^{\circledR}$ software version 5.03 (Graph Pad Software Inc., La Jolla, CA, USA). Baseline demographic and clinical characteristics were presented as medians and interquartile ranges (IQRs). Univariate analysis using the Fisher's exact test was performed for each variable. The level of significance was set at 0.05 .

\section{Nucleotide sequence accession numbers}

The sequences reported in this study were deposited in GenBank under accession numbers KU820990 to KU821019 and KU8823632 to KU883661.

\section{RESULTS}

A total of 38 HIV-positive patients were included in the study. Of these, 30 (79\%) had HIV/HCV coinfection, whiles $8(21 \%)$ had HIV/HBV coinfection. Most patients were male $(\mathrm{n}=27 ; 71 \%)$, and the median age was 49 years (IQR: 44-75 years). With regard to the risk factors for $\mathrm{HIV} / \mathrm{HCV} / \mathrm{HBV}$ acquisition, 22 (58\%) patients were drug users, with 14 (42.1\%) being injection drug users. In general, the patients included in the study had a long duration of HIV infection, with a median duration of 17 years (IQR: 12-25 years); 32 (84.2\%) patients had an undetectable viral load and showed an improvement in cell-mediated immune function, with a median nadir of 147 cells $/ \mathrm{mm}^{3}$ and a CD4 ${ }^{+} \mathrm{T}$-cell count of 452 cells $/ \mathrm{mm}^{3}$. Thirtyseven (97.4\%) patients had been treated with ART for a median duration of 14 years (IQR: 9-25 years).

The HIV pol and/or env genes of all patients were sequenced, with $47.4 \%(n=18)$ of patients belonging to subtype $C, 31.6 \%$ $(\mathrm{n}=12)$ to subtype $\mathrm{B}$, and $21 \%(\mathrm{n}=8)$ to circulating recombinant 
forms (CRFs) (Figure 1). Genetic polymorphisms of the CCR5 co-receptor were evaluated in 35 individuals, and no case of partial deletion was found. Regarding viral receptor usage, there was a predominance of R5 tropism between $\mathrm{B}$ and $\mathrm{C}$ subtypes with no significant difference.

With regard to ARV resistance, six (15.8\%) patients showed mutations related to resistance to nucleoside reverse transcriptase inhibitors (NRTI) and one (2.6\%) showed mutations related to resistance to non-NRTI; however, no mutation to protease inhibitors was found. Three (7.9\%) patients had died. The epidemiological and clinical characteristics according to the HIV subtypes of all participants are summarized in Table 1.

Among the HIV/HBV-coinfected patients, seven (87.5\%) were on ART. Three (43\%) patients received HBV-specific therapy, which comprised a dual therapy of lamivudine and tenofovir, and one (14.3\%) patient received a combination therapy of conventional interferon and lamivudine. There were no records of laboratory investigations of $\mathrm{HBV}$ treatment response.

Among the HIV/HCV-coinfected individuals, 20/30 (66.7\%) were eligible for $\mathrm{HCV}$ therapy based on pegylated interferon alpha and ribavirin (PEG-IFN $\alpha /$ RBV); of these, 10/20 (50\%) achieved sustained virological response (SVR), 9/20 (45\%) showed no response, and 1/20 (5\%) had relapsed. Regarding the SNPs of IL28B (rs12979860), 28/30 (93.3\%) of patients were examined, of which 16 (57.1\%) presented the CC genotype (Table 2).

\section{DISCUSSION}

Most studies on the association of viral and host genetic profiles with the outcome and therapy response in HIV/viral hepatitis-coinfected patients have been conducted in populations infected with HIV-1 subtype B. This is the commonest variant in the USA and Western Europe but represents less than 15\% of HIV-1 infections worldwide. This knowledge should not be directly extrapolated to all subtypes given the significant sequential differences observed in both the structural and regulatory genes of HIV-1 subtypes, which can influence the biological properties of the virus ${ }^{14}$.

A previous study conducted in southern Brazil have reported that subtype $\mathrm{C}$ is more prevalent in the heterosexual population, whereas subtype B is more prevalent in men who have sex with men (MSM) and men who have sex with men and women (MSMW) ${ }^{6}$. This greater predisposition of heterosexual transmission of subtype $\mathrm{C}$ compared with other subtypes seems to be related to the stronger preference for the female genital mucosa, which may also enable vertical transmission ${ }^{15}$.

With regard to the distribution by gender, age, the risk of contamination, and sexual behavior, HIV subtype prevalence in
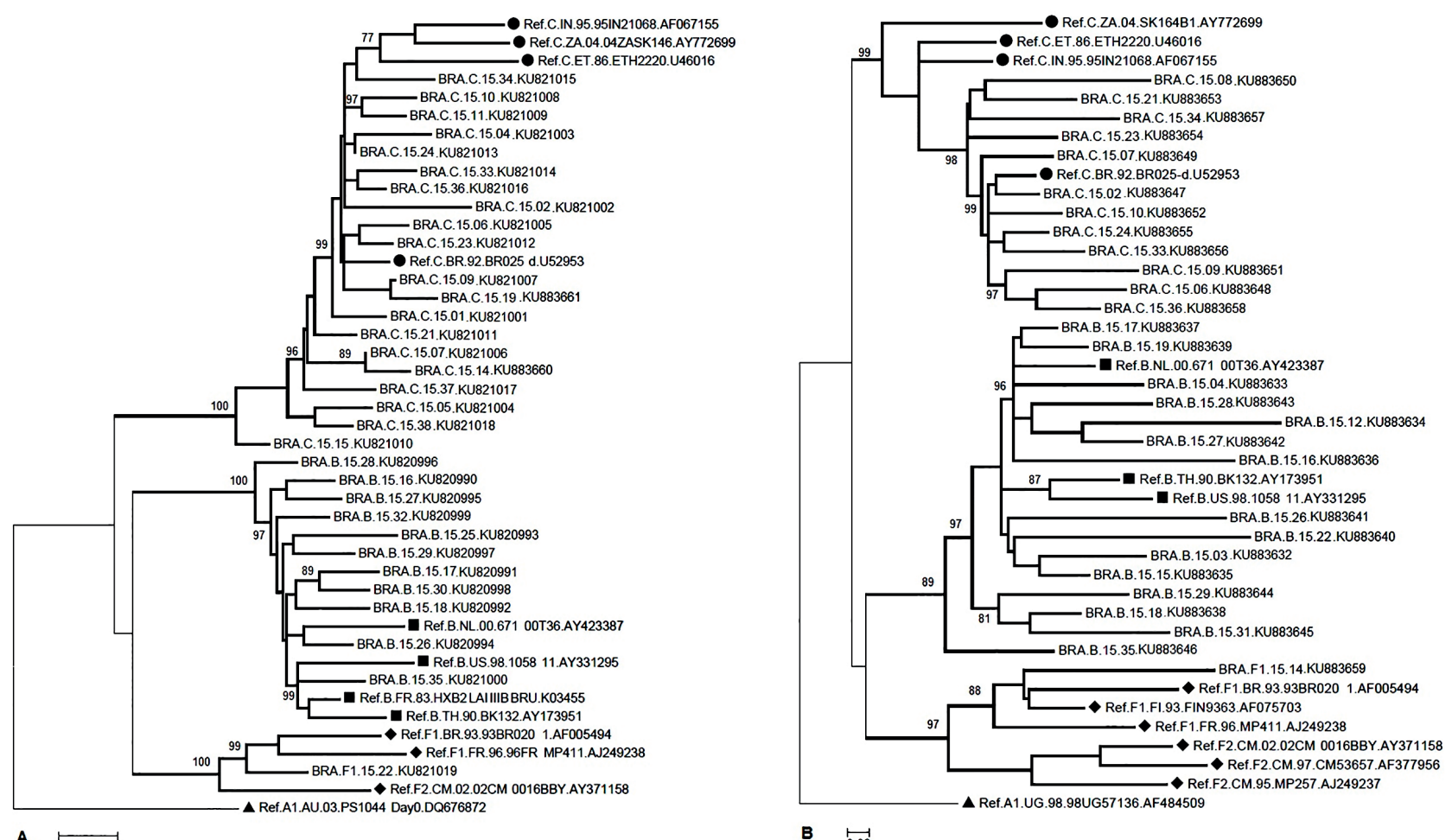

A $\stackrel{0.02}{\longmapsto}$

B $\stackrel{\longmapsto}{0.02}$

FIGURE 1 - Maximum likelihood phylogenetic trees for the pol (A) and env (B) HIV genes from the HIV/HCV- or HIV/HBV-coinfected Brazilian patients. Reference sequences (REF) were obtained from the Los Alamos National Laboratory database (http://www.hiv.lanl.gov) and are indicated by arbitrary symbols ( $\mathbf{\square}=$ Subtype B; $\diamond=$ Subtype F; $\bullet=$ Subtype C; $\hat{\boldsymbol{\varepsilon}}=$ Subtype A). Numbers at branch nodes refer to the bootstrap support (only values greater than $75 \%$ are shown). Scale bar, 0.2 nucleotide substitutions per site. HIV: human immunodeficiency virus; HCV: hepatitis C virus; HBV: hepatitis B virus; BRA: Brazil. 
TABLE 1

Epidemiological, clinical and viral characteristics of coinfected patients according to the HIV subtype.

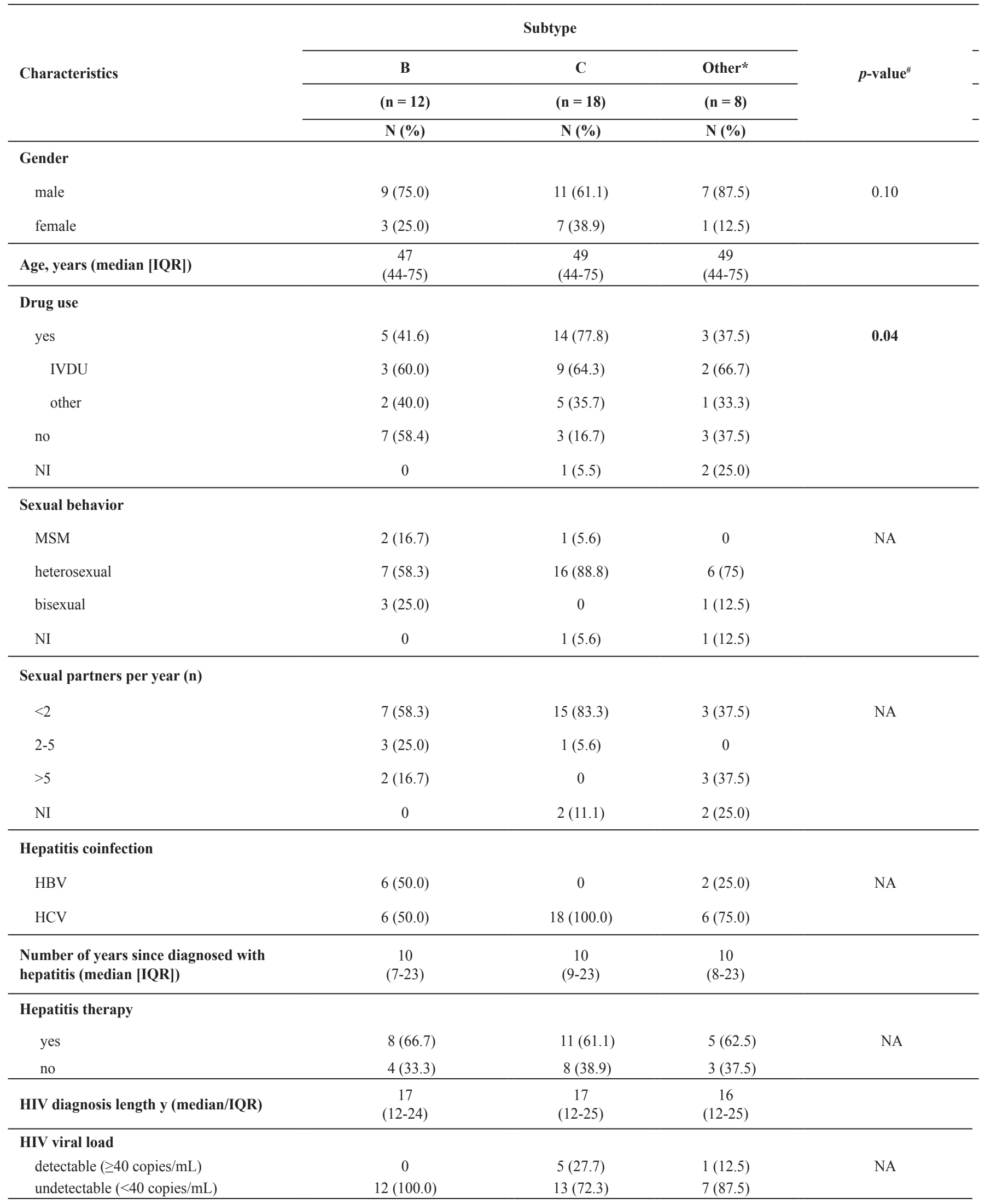

Continue.... 
TABLE 1 - Continuation.

\begin{tabular}{|c|c|c|c|c|}
\hline \multicolumn{5}{|c|}{$\begin{array}{l}\text { CD4 }^{+} \text {T lymphocyte value cells } / \mathrm{mm}^{3} \\
\text { (median [IQR]) }\end{array}$} \\
\hline nadir & $\begin{array}{c}188 \\
(89-445)\end{array}$ & $\begin{array}{c}193 \\
(91-445)\end{array}$ & $\begin{array}{c}133 \\
(83-445)\end{array}$ & \\
\hline current & $\begin{array}{c}397 \\
(283-967)\end{array}$ & $\begin{array}{c}485 \\
(285-1,038)\end{array}$ & $\begin{array}{c}413 \\
(283-1,038)\end{array}$ & \\
\hline no & 0 & 0 & $1(12.5)$ & \\
\hline \multicolumn{5}{|c|}{ CCR5 polymorphism } \\
\hline wild & $12(100.0)$ & $18(100.0)$ & $5(62.5)$ & NA \\
\hline NS & 0 & 0 & $3(37.5)$ & \\
\hline \multicolumn{5}{|l|}{ HIV tropism } \\
\hline Death & $1(8.3)$ & $1(5.6)$ & 0 & NA \\
\hline
\end{tabular}

HIV: human immunodeficiency virus; IQR: interquartile range; IVDU: intravenous drug user; NI: not informed; MSM: men who have sex with men; NA: not applicable; HBV: hepatitis B virus; HCV: hepatitis C virus; CD4 $^{+}$: cluster of differentiation 4+; ART: antiretroviral therapy; CCR5: C-C chemokine receptor type 5; R5: R5-receptor tropic virus; R5/X4: R5/CXR4-receptor tropic virus ; NS: not subtyped; CRF: circulating recombinant forms; *Other: CRF subtypes: BC (6 cases), BF1 (1 case), CF1 (1 case). \#P-value calculated between B and C subtypes. Bold values: statistically significant.

Curitiba shows a higher frequency of subtype B (55\%), followed by subtype C (30\%), subtype F $(7.5 \%)$, and CRFs $(7.5 \%)^{6}$. However, in the present study, the distribution of HIV-1 subtypes found in coinfected patients was different from that reported, with a higher predominance of subtype $\mathrm{C}$ among these patients, and determining the effect of HIV-1 subtypes in the context of coinfection remains a challenge. In this study, some viral and host characteristics of HIV/viral hepatitis-coinfected patients were evaluated in order to gain further knowledge about this issue. Furthermore, the results of the present study are in accord with previous investigations, that most HIV-1 subclade F1 strains circulating in Brazil may contain recombinant genomes ${ }^{16}$.

HIV-1 subtypes may exhibit differences in rates of transmission, disease progression, neurotoxicity, antiretroviral treatment failure profiles, and accuracy of viral load measurements ${ }^{15}$. Several clinical studies have addressed the differences in disease progression between viral subtypes and outcomes. Toulomi et al. ${ }^{17}$ revealed that $\mathrm{CD} 4^{+} \mathrm{T}$ lymphocyte decline was significantly slower for subtype A and CRF02 and marginally slower for subtype C compared to subtype B. In addition, a previous study reported that subtype $\mathrm{D}$ is associated with faster disease progression, rapid $\mathrm{CD} 4^{+} \mathrm{T}$ cell decline, and a higher rate of treatment failure compared to subtypes A, B, and $\mathrm{C}^{18}$. In vitro studies suggested that the replication of subtype $\mathrm{C}$ is less competent than that of subtype $\mathrm{B}^{19}$. In this study, the mutations related to resistance to ART did not affect clinical features, as most patients $(\mathrm{n}=32 ; 94.7 \%)$ showed a good response to HIV treatment.
With regard to the CCR5 polymorphisms, no case of CCR5 -32 mutation was found. Previous studies in the Brazilian population showed that less than $10 \%$ of the investigated individuals carried the heterozygous CCR $5 \Delta-32$ genotype ${ }^{20,21}$. The small number of participants included in the present study may have affected the detection of this mutation.

The application of bioinformatic tools in co-receptor usage determination has been widely investigated and could provide an alternative approach in clinical practice for screening candidates for CCR5 antagonist therapy, especially when confirmatory assays for co-receptor usage determination are unavailable ${ }^{22}$. In this study, the Geno2pheno and Phenoseq analyses showed R5 and R5/X4 variants in 22/34 (64.7\%) and $12 / 34(35.3 \%)$ HIV samples, respectively. However, we found no case of CCR $5 \Delta-32$ heterozygosity, and it is possible that other genetic alterations or levels of expression, including specific cellular proteins such as restriction factors, APOBEC3, TRIM5, and Tetherin ${ }^{23}$, could be associated with disease progression. In a study of patients with a slower progression to acquired immune deficiency syndrome conducted in the municipality of Curitiba, it was noted that the R5 variant was the most common type for this patient group $(95 \%)^{24}$. However, all these studies were conducted in HIV-monoinfected patients; thus, we do not know if the behavior of HIV is different in patients coinfected with viral hepatitis. Because of the effect of coinfection on the progression of the disease, we expected that a greater number of patients would express the R5/X4 co-receptor. 
TABLE 2

HIV, host genetic characteristics, pathological findings, and therapy response according to HCV genotype.

\begin{tabular}{|c|c|c|c|c|}
\hline \multirow{2}{*}{ Characteristics } & \multicolumn{4}{|c|}{$\begin{array}{c}\text { HCV genotypes } \\
\mathbf{N}=30^{*}\end{array}$} \\
\hline & $\mathrm{n}=\mathbf{2 0}(\%)$ & $n=1(\%)$ & $n=6(\%)$ & $\mathrm{n}=\mathbf{1}(\%)$ \\
\hline \multicolumn{5}{|l|}{ HIV subtype } \\
\hline B & $4(20.0)$ & 0 & $1(17.0)$ & $1(100.0)$ \\
\hline $\mathrm{C}$ & $10(50.0)$ & $1(100.0)$ & $5(83.0)$ & 0 \\
\hline \multicolumn{5}{|l|}{ Hepatic biopsy ${ }^{*}$} \\
\hline yes $(\mathrm{N}=25)$ & $18(90.0)$ & 0 & $6(100.0)$ & $1(100.0)$ \\
\hline hepatic steatosis $(\mathrm{N}=16)$ & $11(61.1)$ & 0 & $4(66.7)$ & $1(100.0)$ \\
\hline $\operatorname{normal}(\mathrm{N}=1)$ & $1(5.6)$ & 0 & 0 & 0 \\
\hline no $(\mathrm{N}=5)$ & $2(10.0)$ & $1(100.0)$ & 0 & 0 \\
\hline \multicolumn{5}{|l|}{ HCV therapy } \\
\hline yes $(N=20)$ & $15(75)$ & 0 & $4(66.7)$ & 1 \\
\hline $\operatorname{SVR}(\mathrm{N}=10)$ & $5(33.3)$ & 0 & $4(100.0)$ & $1(100.0)$ \\
\hline null response $(\mathrm{N}=9)$ & $9(60.0)$ & 0 & 0 & 0 \\
\hline \multicolumn{5}{|l|}{ IL28B (rs12979860) } \\
\hline NS & $2(10.0)$ & 0 & 0 & 0 \\
\hline
\end{tabular}

HIV: human immunodeficiency virus; HCV: hepatitis C virus; SVR: sustained virological response; IL28B: interleukin 28B; NS: not subtyped; CRF: circulating recombinant forms; * HCV genotyping was not performed in two patients. ${ }^{* *}$ Other: CRF subtypes $=\mathrm{BC}$ ( 6 cases), BF1 (1 case), CF1 (1 case).

In Brazil, data on HBV/HIV coinfection are limited, and some studies conducted in the southern, southeastern, and midwestern regions revealed a prevalence ranging from 3.7 to $36.9 \%{ }^{25-27}$. In this study, we identified only a small number of HBV/HIV-coinfected individuals probably because of the low frequency of laboratory investigations for HBV in drug users, as well as the routine vaccination against HBV in HIV-infected patients.

Vaccination against HBV for high-risk individuals and children younger than 1 year of age was included in the National Immunization Program in Brazil in 1996; in 2001, immunization against HBV was expanded to include young people up to 19 years of age ${ }^{28}$. Currently, the vaccination program has been extended to individuals up to 49 years of age, in addition to all HIV-infected patients ${ }^{29}$. However, as HIV+ individuals respond poorly to the HBV vaccine, regular monitoring of the immunological status in these patients is recommended ${ }^{30}$.

Previous studies have reported that in the treatment of HCV/ HIV-coinfected patients on dual therapy, SVR was achieved in approximately $20-40 \%$ of those with HCV genotype- $1 / 4$ (GT1/4) and 50-60\% of those with HCV genotype 2/3 (GT2/3) ${ }^{31}$. The baseline predictors for PEG-IFN $\alpha /$ RBV therapy response include age, sex, HCV genotype, HCV viral load, liver fibrosis, and SNPs of the $I L 28 B$ gene $^{32}$. The efficiency of treatment with PEG-IFN $\alpha /$ RBV was limited in patients with HCV monoinfection, and only $45-55 \%$ of the patients infected with HCV genotype-1 (GT1) achieved SVR ${ }^{33}$.

The $I L 28 B$ gene encodes interferon- $\lambda 3$, which has strong antiviral activity, and this cytokine can activate cell signaling 
pathways that control viral replication ${ }^{34}$. Recent studies have demonstrated the effect of some favorable genotypes (the CC and TT genotypes, and the $\mathrm{C}$ and $\mathrm{T}$ alleles of polymorphisms rs8099917 and rs12979860, respectively) on the response to the standard treatment for chronic hepatitis $\mathrm{C}$, as well as their relationship with spontaneous HCV clearance in mono- and coinfected individuals ${ }^{29,35}$.

Lunge et al. ${ }^{36}$ reported the correlation between the SNP rs12979860 and the spontaneous clearance of HCV in a population of HIV-coinfected Brazilian patients. The presence of the CT and TT genotypes increased the risk of developing chronic infection by three times compared to the CC genotype. In this study, 16/30 (53.3\%) individuals presented favorable genotypes (CC) for the SNP rs12979860. However, only 8/19 (42.1\%) achieved SVR; we believe that other factors are associated with the outcome. Bertol et al ${ }^{37}$ suggested that SNPs near the $I L 28 B$ gene exert a significant influence on the establishment of HCV infection in HCV-monoinfected patients, contributing to a better understanding of the susceptibility, natural history of $\mathrm{HCV}$ infection, and the high rate of SRV in this patient group. However, Martin et al..$^{38}$ and Nattermann et al..$^{39}$ did not observe any correlation between the SNP rs12979860 and HIV-monoinfected patients; there was no significant difference in the susceptibility to HIV infection, the progression of the disease, or the clinical and laboratory parameters such as viral load. Therefore, SNPs of the IL28B gene seem to be associated with HIV only when there is coinfection with $\mathrm{HCV}^{39}$.

The small number of participants is the major limitation of this study; therefore, it was not possible to make inferences about the impact of viral characteristics and some host genetic factors on the outcome. However, with the currently high survival rate of HIV+ individuals, HCV-related liver disease in coinfected patients is becoming a major cause of morbidity and mortality, and the burden of $\mathrm{HIV} / \mathrm{HCV}$ coinfection is poorly understood ${ }^{4}$. In Brazil, descriptive studies of this nature face several difficulties, including the need for expertise and financial investment to perform laboratory tests, resulting in cohorts with a small number of cases.

Despite these limitations, this study provides insights regarding the clinical and laboratory profile of HIV/viral hepatitis-coinfected patients in the country. In addition, our findings emphasize the importance of screening for viral hepatitis when individuals are identified as HIV positive and vice versa. Moreover, the management of viral hepatitis should be integrated into HIV treatment programs, including effective treatment for a triple infection ( $\mathrm{HIV} / \mathrm{HCV} / \mathrm{HBV})$, as well as vaccination for $\mathrm{HBV}$-negative individuals with HIV to reduce HIV-related morbidity and mortality.

In conclusion, in the present case series, a higher frequency of HIV-1 subtype C was found in patients with HIV/viral hepatitis coinfection, and there was a predominance of R5 tropism between both $\mathrm{B}$ and $\mathrm{C}$ subtypes. Genetic polymorphisms for the CCR5 co-receptor were not found, and most patients presented the favorable genotype regarding the SNPs of IL28B. Further larger-scale and long-term studies are needed to assess the effect of HIV-1 subtypes on the progression of viral hepatitis, as well as for the analysis of other markers that may influence the interaction between pathogens and the host response, affecting its outcome.

\section{Acknowledgements}

The authors thank the virology laboratory team for helping us with the technical training.

\section{Conflict of interest}

The authors declare that they have no competing interests.

\section{Financial support}

This work was supported by grants from Conselho Nacional de Desenvolvimento Científico e Tecnológico (CNPq) (\#444819/2014-2 MCTI/ CNPQ/Universal 14/2014). SMR is on a fellowship from CNPq .

\section{REFERENCES}

1. Lacombe K, Rockstroh J. HIV and viral hepatitis coinfections: advances and challenges. Gut. 2012;61(Suppl 1):i47-58.

2. Brandão NAA, Pfrimer IAH, Martelli CMT, Turchi MD. Prevalence of hepatitis $\mathrm{B}$ and $\mathrm{C}$ infection and associated factors in people living with HIV in Midwestern Brazil. Brazilian J Infect Dis. 2015;19(4):426-30.

3. Kuehlkamp VM, Schuelter-Trevisol F. Prevalence of human immunodeficiency virus/hepatitis C virus co-infection in Brazil and associated factors: a review. Brazilian J Infect Dis. 2013;17(4): 455-63.

4. Buskin SE, Barash EA, Scott JD, Aboulafia DM, Wood RW. Hepatitis $\mathrm{B}$ and $\mathrm{C}$ infection and liver disease trends among human immunodeficiency virus-infected individuals. World $\mathrm{J}$ Gastroenterol. 2011;17(4):1807-16.

5. Kumar R, Singla V, Kacharya Sk. Impact and management of hepatitis B and hepatitis C virus co-infection in HIV patients. Trop Gastroenterol. 2008;29(3):136-47.

6. Raboni SM, de Almeida SM, Rotta I, Ribeiro CEL, Rosario D, Vidal LR, et al. Molecular epidemiology of HIV-1 clades in Southern Brazil. Mem Inst Oswaldo Cruz. 2010;105(8):1044-9.

7. Raboni SM, Tuon FF, Beloto NCP, Demeneck H, Oliveira A, Largura D, et al. Human immunodeficiency virus and hepatitis C virus/hepatitis B virus co-infection in Southern Brazil: clinical and epidemiological evaluation. Brazilian J Infect Dis. 2014;18(6): 664-8.

8. Bello G, Passaes CP, Guimarães ML, Lorete RS, Matos Almeida SE, Medeiros RM, et al. Origin and evolutionary history of HIV-1 subtype C in Brazil. AIDS. 2008;22(15):1993-2000.

9. Delwart EL, Shpaer EG, Louwagie J, McCutchan FE, Grez M, Rübsamen-Waigmann $\mathrm{H}$, et al. Genetic relationships determined by a DNA heteroduplex mobility assay: analysis of HIV-1 env genes. Science. 1993;262(5137):1257-61.

10. Waddell PJ, Steel M. General time-reversible distances with unequal rates across sites: mixing $\gamma$ and inverse Gaussian distributions with invariant sites. Mol Phylogenet Evol. 1997;8(3):398-414.

11. Lole KS, Bollinger RC, Paranjape RS, Gadkari D, Kulkarni SS, Novak NG, et al. Full-length human immunodeficiency virus type 1 genomes from subtype C-infected seroconverters in India, with evidence of intersubtype recombination. J Virol. 1999;73(1):152-60. 
12. Michael NL, Chang G, Loum LG, Mascola JR, Dondero D, Birx DL, et al. The role of viral phenotype and CCR-5 gene defects in HIV-1 transmission and disease progression. Nat Med. 1997;3(3):338-40.

13. Ferreira CS, Abreu RM, da Silva MC, Ferreira AS, Nasser PD, Carrilho FJ, et al. A fast and cost-effective method for identifying a polymorphism of interleukin 28B related to hepatitis C. PLoS One. 2013;8(10):e78142.

14. Rivero-Juárez A, Camacho A, Merchante N, Pérez-Camacho I, Macias J, Ortiz-Garcia C, et al. Incidence of liver damage of uncertain origin in hiv patients not co-infected with HCV/HBV. PLoS One. 2013;8(7):e68953.

15. Hemelaar J. The origin and diversity of the HIV-1 pandemic. Trends Mol Med. 2012;18(3):182-92.

16. Easterbrook PJ, Smith M, Mullen J, O'Shea S, Chrystie I, de Ruiter A, et al. Impact of HIV-1 viral subtype on disease progression and response to antiretroviral therapy. J Int AIDS Soc. 2010;13:4.

17. Touloumi G, Pantazis N, Pillay D, Paraskevis D, Chaix M-L, Bucher HC, et al. Impact of HIV-1 subtype on CD4 count at HIV seroconversion, rate of decline, and viral load set point in European seroconverter cohorts. Clin Infect Dis. 2013;56(6):888-97.

18. Tebit DM, Nankya I, Arts EJ, Gao Y. HIV diversity, recombination and disease progression: how does fitness "fit" into the puzzle? AIDS Rev. 2007;9(2):75-87.

19. Ariën KK, Abraha A, Quiñones-Mateu ME, Kestens L, Vanham G, Arts EJ. The replicative fitness of primary human immunodeficiency virus type 1 (HIV-1) group M, HIV-1 group O, and HIV-2 isolates. J Virol. 20051;79(14):8979-90.

20. Passos Jr GAS, Proença Picanço V. Frequency of the $\Delta$ ccr5 deletion allele in the urban Brazilian population. Immunol Lett. 1998;61 (2-3):205-7.

21. Muxel SM, Borelli SD, Amarante MK, Voltarelli JC, Aoki MN, de Oliveira CEC, et al. Association study of CCR5 delta 32 polymorphism among the HLA-DRB1 Caucasian population in Northern Paraná, Brazil. J Clin Lab Anal. 2008;22(4):229-33.

22. Santos JS, Ribeiro CE, Almeida SM, Raboni SM. Clinical, virologic and immunological outcomes in a cohort of long-term nonprogressor HIV infected patients, Southern Brazil. J AIDS Clin Res. 2015;6(9):502.

23. Franco E, Bagnato B, Marino MG, Meleleo C, Serino L, Zaratti L. Hepatitis B: epidemiology and prevention in developing countries. World J Hepatol. 2012;4(3):74-80.

24. Souza MG, Passos ADC, Machado AA, Figueiredo JFC, Esmeraldino LE. HIV and hepatitis B virus co-infection: prevalence and risk factors. Rev Soc Bras Med Trop. 2004;37(5):391-5.

25. Treitinger A, Spada C, Silva EL, Miranda AF, Oliveira OV, Silveira $\mathrm{MV}$, et al. Prevalence of serologic markers of HBV and HCV infection in HIV-1 seropositive patients in Florianópolis, Brazil. Braz J Infect Dis. 1999;3(1):1-5.
26. Ministério da Saúde. Secretaria de Vigilância em Saúde. Programa Nacional de Imunização: 30 anos. Brasília: Ministério da Saúde; 2003. 212 p.

27. Ministério da Saúde. Secretaria de Vigilância em Saúde. Departamento de DST, Aids e das Hepatites Virais. Protocolo Clínico e Diretrizes Terapêuticas para o Manejo da Infecção por HIV em Adultos. Brasília: Ministério da Saúde; 2003. 227 p.

28. Rockstroh JK, Bhagani S. Managing HIV/hepatitis C co-infection in the era of direct acting antivirals. BMC Med. 2013;11:234.

29. Jiménez-Sousa MA, Fernández-Rodríguez A, Guzmán-Fulgencio M, García-Álvarez M, Resino S. Meta-analysis: implications of interleukin-28B polymorphisms in spontaneous and treatmentrelated clearance for patients with hepatitis C. BMC Med. 2013;11(1):6.

30. Kourtis AP, Bulterys M, Hu DJ, Jamieson DJ. HIV-HBV Cinfection - AGlobal Challenge. N Engl J Med. 2012;366(19):1749-52.

31. Lens García S, Coto-Llerena M, Pérez del Pulgar Gallart S, Forns Bernhardt X. Genetics and hepatitis C treatment: towards a personalized treatment? Gastroenterol Hepatol. 2011;34(5):352-60.

32. Balagopal A, Thomas DL, Thio CL. IL28B and the control of hepatitis C virus infection. Gastroenterology. 2010;139(6):1865-76.

33. Thomas DL, Thio CL, Martin MP, Qi Y, Ge D, O'Huigin C, et al. Genetic variation in IL28B and spontaneous clearance of hepatitis C virus. Nature. 2009;461(7265):798-801.

34. Suppiah V, Moldovan M, Ahlenstiel G, Berg T, Weltman M, Abate $\mathrm{ML}$, et al. IL28B is associated with response to chronic hepatitis C interferon-alpha and ribavirin therapy. Nat Genet. 2009;41(10):1100-4.

35. Tanaka Y, Nishida N, Sugiyama M, Kurosaki M, Matsuura K, Sakamoto N, et al. Genome-wide association of IL28B with response to pegylated interferon- $\alpha$ and ribavirin therapy for chronic hepatitis C. Nat Genet. 2009;41(10):1105-9.

36. Lunge VR, da Rocha DB, Béria JU, Tietzmann DC, Stein AT, Simon D. IL28B polymorphism associated with spontaneous clearance of hepatitis C infection in a Southern Brazilian HIV type 1 population. AIDS Res Hum Retroviruses. 2012;28(2):215-9.

37. Bertol BC, Moreira S, Garcia RFL, Ferreira LE, Debortoli G, Pinho MSL, et al. IL28B gene polymorphisms in mono- and HIVcoinfected chronic hepatitis $C$ patients. Front Microbiol. 2015; 6:153.

38. Martin MP, Qi Y, Goedert JJ, Hussain SK, Kirk GD, Keith Hoots W, et al. IL28B polymorphism does not determine outcomes of hepatitis B virus or HIV infection. J Infect Dis. 2010;202(11):1749-53.

39. Nattermann J, Vogel M, Nischalke HD, Danta M, Mauss S, Stellbrink HJ, et al. Genetic variation in IL28B and treatmentinduced clearance of hepatitis $\mathrm{C}$ virus in HIV-positive patients with acute and chronic hepatitis C. J Infect Dis. 2011;203(5):595-601.

40. Platt L, Easterbrook P, Gower E, McDonald B, Sabin K, McGowan $\mathrm{C}$, et al. Prevalence and burden of $\mathrm{HCV}$ co-infection in people living with HIV: A global systematic review and meta-analysis. Lancet Infect Dis. 2016;16(7):797-808. 